\title{
Temperature Dependent Reproduction and Survival of the Soil Nematode Pristionchus maupasi In Vitro
}

\author{
Jørn Grønvold ${ }^{* 1}$, Per Moestrup Jensen ${ }^{1}$, Niels Martin Schmidt ${ }^{2}$ and Christian Kapel ${ }^{1}$ \\ ${ }^{I}$ Department of Agriculture and Ecology, Faculty of Life Sciences, University of Copenhagen, 40 Thorvaldsensvej, DK-1871 \\ Frederiksberg C, Copenhagen, Denmark \\ ${ }^{2}$ Section for Climate Effects and System Modelling, Department of Arctic Environment, National Environmental Research \\ Institute, Aarhus University, Frederiksborgvej 399, PO Box 358, DK-4000 Roskilde, Denmark
}

\begin{abstract}
In the present study, the reproduction potential and survival capability of the soil nematode Pristionchus maupasi was followed in $10 \mathrm{~cm}^{2}$ Petri dishes at different constant temperatures: $5,10,15,20,25$ and $30^{\circ} \mathrm{C}$. The experiment started by placing nematode eggs on each dish. The minimum number of days from eggs, at start, to adult egg producing nematodes, decreased from 7 days at $10^{\circ} \mathrm{C}$ to 3 days at $25^{\circ} \mathrm{C}$. At $5^{\circ} \mathrm{C}$ no eggs hatched, and at $30^{\circ} \mathrm{C}$ the released larvae did not develop into egg producing adults. After 7 days all eggs had hatched in the interval between 15 and $30^{\circ} \mathrm{C}$ and $87 \%$ at $10^{\circ} \mathrm{C}$. From hatched eggs the $1^{\text {st }}$ generation nematodes evolved.

At day 4 , the number of $1^{\text {st }}$ generation nematodes was almost similar at temperatures ranging from 10 to $25^{\circ} \mathrm{C}$, while the number at $30^{\circ} \mathrm{C}$ was significantly lower. The $1^{\text {st }}$ generation adult nematodes gave rise to a $2^{\text {nd }}$ generation, which did not develop to fertility, but became arrested $3^{\text {rd }}$ stage "dauerlarvae", maybe due to reduced food supplies and increased concentration of wastes. From 100 'eggs at start', 10000 to $140002^{\text {nd }}$ generations "dauerlarvae" developed at temperatures between 10 and $20^{\circ} \mathrm{C}$. In the interval from 10 to $25^{\circ} \mathrm{C}$, a substantial number of these survived more than 2 months.
\end{abstract}

Keywords: Soil nematode, Pristionchus maupasi, Reproductive capacity, Survival, Temperature.

\section{INTRODUCTION}

The top soil nematode community participates in the decomposition of organic matter. We found that one square meter of our experimental field (Copenhagen, Denmark) harboured approximately four million nematodes in the upper $20 \mathrm{~cm}$ of soil in the summer. During winter numbers were reduced to approximately three millions per square meter.

One of the species in our field is Pristionchus maupasi Potts (Diplogastridae). It is a hermaphroditic nematode, which has been found in soil, seashore mud, decaying potatoes and meat, excrements from a snail, and in cattle dung [1]. Moreover, $P$. maupasi may be phoretically associated with beetles of the family Hydrophilidae [1] and scarab beetles of the genera Melolontha and Cetonia [2]. Pristionchus maupasi feed on bacteria, but the specialised buccal cavity possibly allows utilization of other food items, e.g. fungi and nematodes. Sohlenius [3] observed nematode predatory behaviour by this species.

The aim of the present in vitro study was to evaluate the reproduction potential and survival capability of $P$. maupasi at different constant temperatures, to enrich the knowledge base of soil nematodes.

*Address correspondence to this author at the Department of Agriculture and Ecology, Faculty of Life Sciences, University of Copenhagen, 40 Thorvaldsensvej, DK-1871 Frederiksberg C, Copenhagen, Denmark;

Tel: 45353326 70; Fax: 45353326 70; E-mail: groenvold50@yahoo.dk

\section{MATERIALS AND METHODOLOGY}

\section{Stock Cultures of the Soil Nematode $P$. maupasi}

Pristionchus maupasi was cultivated on half the concentration of Nigons agar (1:2) [4]. The medium was inoculated with the bacterium Pseudomonas fluorescens (Trevisan) Migula as feed for the nematodes. Nematode eggs were collected for the experiment as described below.

\section{Population Dynamics of $P$. maupasi at Different Constant Temperatures}

For identification all experimental Petri dishes $\left(10 \mathrm{~cm}^{2}\right)$ were given an individual number at start. Technically it was not possible to place the same number of eggs on the experimental dishes. Therefore, known numbers (between 30 and 50) of $P$. maupasi eggs were picked up on small agar lumps $\left(3 \times 3 \mathrm{~mm}^{2}\right)$ from stock cultures and carefully placed at the centre of the experimental Petri dishes containing modified Nigons medium $(1: 2)$. In this way individual dishes were inoculated with known numbers of eggs at start. The bacterium $P$. fluorescens spread from the inoculation lumps together with the migrating newborn $1^{\text {st }}$ generation larvae and served as food for the growing P. maupasi population. Petridishes were placed in the dark in climatic chambers at the following constant temperatures: 5 , $10,15,20,25$ and $30^{\circ} \mathrm{C}$. The $1^{\text {st }}$ generation grew up and produced eggs, which resulted in a $2^{\text {st }}$ generation of nematodes.

At intervals (1, 2, 3, 4, 7, 10, 14, 17, 21, 28, 35, 43, 56, 63, 73 and 80 days after experimental start) nematodes were 
counted on the entire surface of each Petri dish until the $2^{\text {nd }}$ generation of $P$. maupasi became numerous. Then the nematodes were enumerated using 3 fixed small counting areas (1/4 $\mathrm{cm}^{2}$ ) on each dish. Based on these counting's numbers in each $10 \mathrm{~cm}^{2}$ Petri dish were calculated. At each temperature the experiment was performed in triplicates.

Over time, the inspections of the Petri dishes made it possible to determine a) the percentage of $P$. maupasi eggs that hatched, b) the minimum number of days from eggs, at start, to adult egg-producing $1^{\text {st }}$ generation nematodes and c) the number of nematodes (pre-adults and adults, not including eggs) of the $1^{\text {st }}$ and $2^{\text {nd }}$ generation of P. maupasi in each Petri dish. A flow chart of the experiment is shown in Fig. (1). As described above, the number of eggs present at the start of the experiment varied for each Petri dish. For comparison, the 'number of nematodes' in Fig. 3 and 4 was proportionally calculated as if 100 eggs had been placed on each Petri dish at the beginning. It was done in the following way: ((Number of nematodes counted on the different days X 100)/ (Exact number of eggs placed on each dish at start)).

\section{Statistical Evaluation}

The number of $1^{\text {st }}$ generation larvae (Fig. 3) was evaluated by a t-test. The tests were executed on $\log (n+1)$ transformed data under a generalised linear mode (PROC GLM) using the associated LSMEANS statement that provide paired t-test for given temperatures. Results are provided for observation day 1 , $4,7,17$ and 80, which adequately defines the statistical differences during the experiment.

\section{RESULTS}

The 'eggs at start' developed differently at various temperatures. At $5^{\circ} \mathrm{C}$ no eggs hatched, but at $10^{\circ} \mathrm{C} 50 \%$ had hatched

Flow chart of the experiment

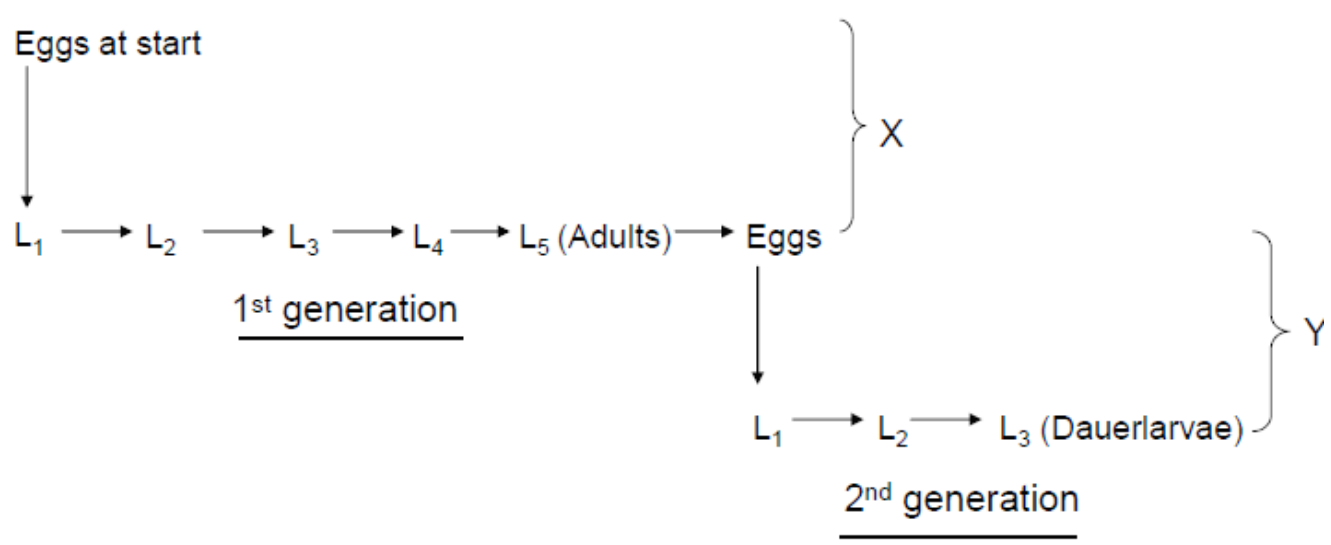

$$
\begin{aligned}
& X=\text { Minimum generation time from eggs at start to eggs in } 1 \text { st generation }\left(T_{\min }\right) \\
& Y=\text { Estimate of net reproductive rate } R_{o} \text { (max. } 2^{\text {nd }} \text { generation/ max. } 1^{\text {st }} \text { generation) }
\end{aligned}
$$

Fig. (1). Flow chart of the experiment, starting as eggs and ending as $2^{\text {nd }}$ generation 'dauerlarvae'. $\mathrm{L}_{1}, \mathrm{~L}_{2}, \mathrm{~L}_{3}, \mathrm{~L}_{4}$ and $\mathrm{L}_{5}$ indicate progressive larval stages. The fifth stage $\left(\mathrm{L}_{5}\right)$ becomes egg laying adults.

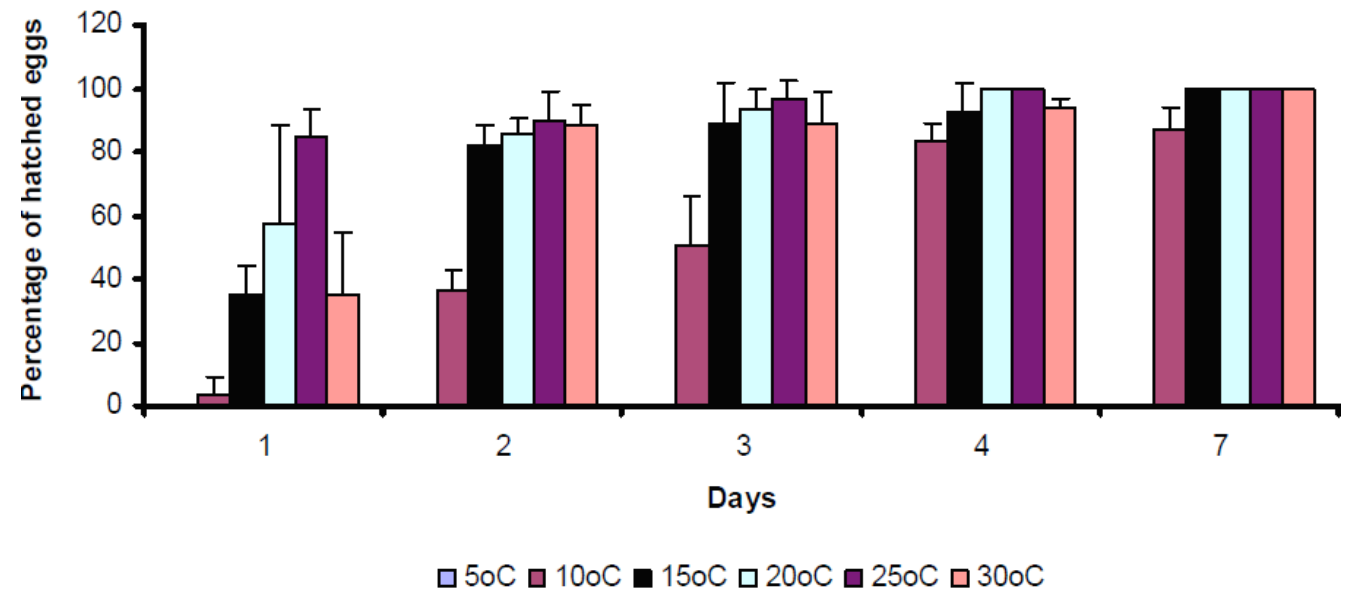

Fig. (2). The mean percentage of $P$. maupasi eggs that hatched over time at different constant temperatures (n=3). + S.D. is shown as vertical bars. 
after just 3 days and $87 \%$ had hatched on day 7 . At the following temperatures $10,15,20,25$ and $30^{\circ} \mathrm{C}$ the hatching by day 2 was $36,82,86,90$ and $88 \%$, respectively. After 7 days all eggs had hatched in the interval between 15 and $30{ }^{\circ} \mathrm{C}$ and $87 \%$ at $10{ }^{\circ} \mathrm{C}$ (Fig. 2). From hatched eggs the $1^{\text {st }}$ generation nematodes evolved.

On the first day of observation more $1^{\text {st }}$ generation larvae were found at 15,20 and $25^{\circ} \mathrm{C}$, than at 5,10 and $30^{\circ} \mathrm{C}$ (t-test, $\mathrm{P}$ $<0.01$ ), which divided them in a high and low temperature hatching group (Fig. 3). At day 4, the number of 1st generation nematodes was very similar over the temperature range from 10 to $25^{\circ} \mathrm{C}$, while the number at $30^{\circ} \mathrm{C}$ was significantly lower (t-test, $\mathrm{P}<0.002$ ). The population sizes at 15,20 and $25^{\circ} \mathrm{C}$ were comparable for the rest of the experiment, except at day 7 when populations at 15 and $25^{\circ} \mathrm{C}$ were significantly different (t-test, $\mathrm{P}=0.01)($ Fig. 3). In the time interval from day 10 to day 35 the population level of nematodes at $10{ }^{\circ} \mathrm{C}$ continued to be lager than populations at 15,20 and $25{ }^{\circ} \mathrm{C}$ (t-test, $\mathrm{P}<0.001$ ) (Fig. 3). At day 43 and onwards only few of the $1^{\text {st }}$ generation nematodes were still living.

At $30^{\circ} \mathrm{C}$ the hatched nematodes did not develop to adult egg producing $1^{\text {st }}$ generation individuals, and they died so quickly that the average number of survivors never exceeded 38 nematodes out of 100 eggs (Fig. 3). Between 10 and $25^{\circ} \mathrm{C}, 100$ eggs resulted in at least 80 nematodes, which became $1^{\text {st }}$ generation adults. According to Fig. (3) the survival of the majority of the $1^{\text {st }}$ generation was not longer than 43 days.

Taking all three replicates into account, the minimum number of days from hatching to egg producing $1^{\text {nd }}$ generation adults (minimum generation time: $\mathrm{T}_{\min }$ ) was observed to be 7 , $5,4,3$ at $10,15,20$ and $25^{\circ} \mathrm{C}$, respectively.

The $2^{\text {nd }}$ generation of $P$. maupasi (Fig. 4) did not become fertile, but "dauerlarvae" (arrested development in the third larval stage). This made it possible to identify the $1^{\text {st }}$ generation nematodes as they were the only adults in the Petri dishes. Temperatures between 10 and $20^{\circ} \mathrm{C}$ were acceptable for $P$. maupasi to build up a large $2^{\text {nd }}$ generation of "dauerlarvae" (Fig. 4). Between 10 and $20^{\circ} \mathrm{C}$ a substantial number of "dauerlarvae" survived until the end of the experiment at day 80 (Fig. 4). At 10,15 and $20^{\circ} \mathrm{C}$ the number of "dauerlarvae" that survived 73 days were 3574,5930 and 8249 , respectively. But at $25^{\circ} \mathrm{C}$ there were no survivors at 21 days (Fig. 4).

\section{DISCUSSION}

The present results indicate that the temperature-niche breadth for population increase of $P$. maupasi range from $10^{\circ} \mathrm{C}$ to $25^{\circ} \mathrm{C}$. The highest number of $2^{\text {nd }}$ generation $P$. maupasi

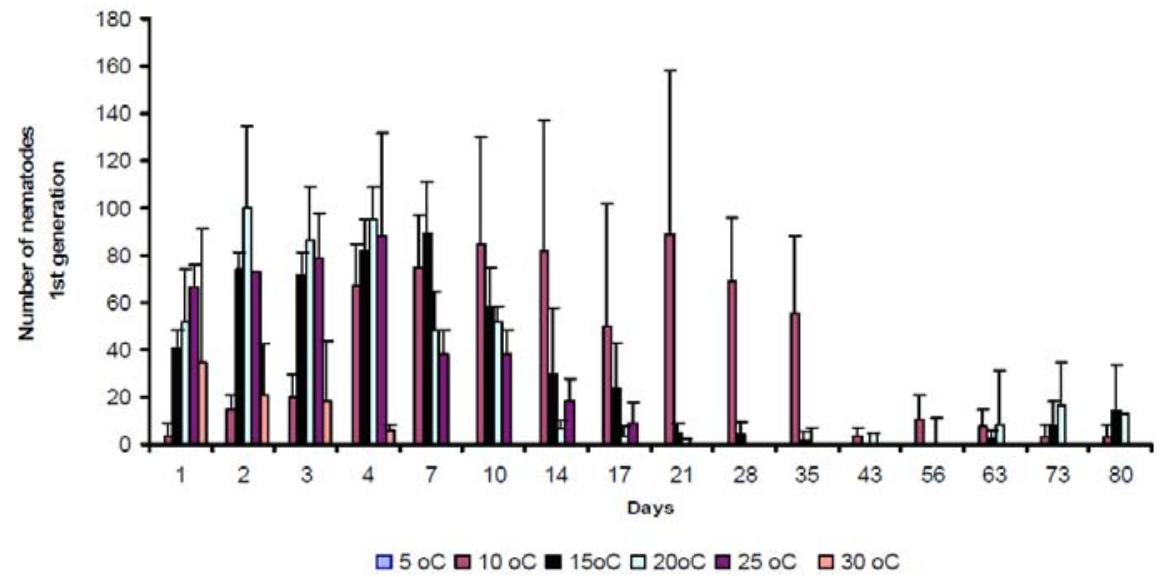

Fig. (3). The mean number of nematodes (adults and pre-adults) of the $1^{\text {st }}$ generation of $P$. maupasi on $10 \mathrm{~cm}^{2}$ Petri dishes (n=3). - The number of nematodes is calculated as if 100 nematode eggs had been placed on the agar at the start of the experiment. +S.D. is shown as vertical bars.

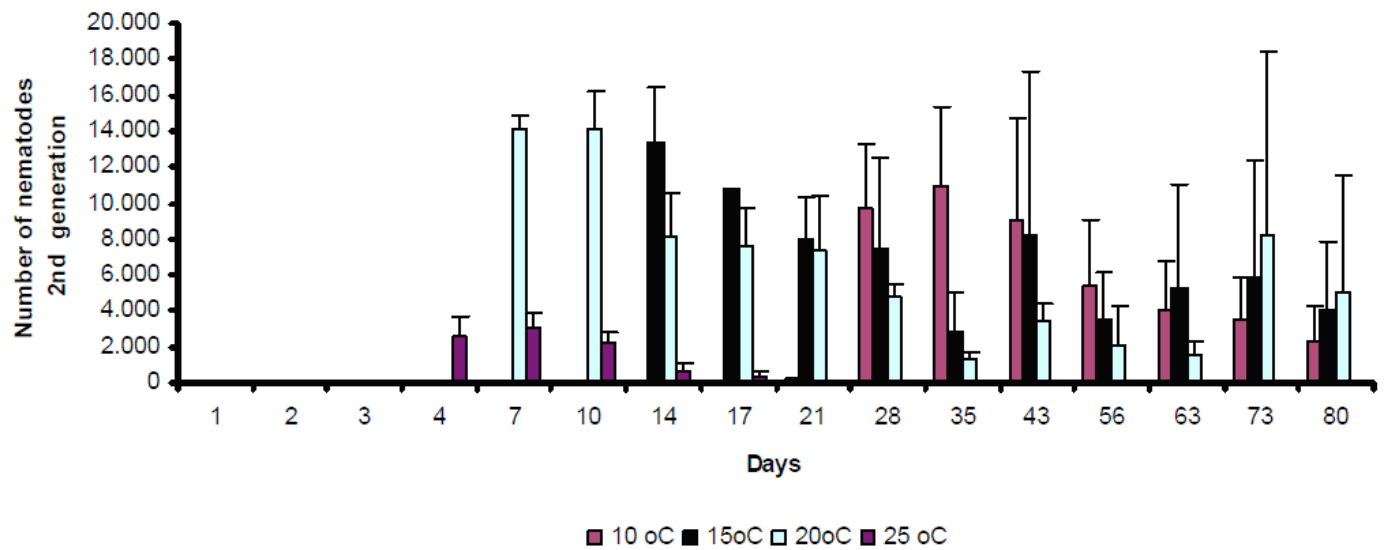

Fig. (4). The mean number of nematodes of the $2^{\text {nd }}$ generation of $P$. maupasi on $10 \mathrm{~cm}^{2}$ Petri dishes (n=3). The $2^{\text {nd }}$ generation of $P$. maupasi did not develop to fertility, but became "dauerlarvae". A $2^{\text {nd }}$ generation did not develop at $5^{\circ} \mathrm{C}$ and $30^{\circ} \mathrm{C}$. - The number of nematodes is calculated as if 100 nematode eggs had been placed on the agar at the start of the experiment. + S.D. is shown as vertical bars. 
nematodes (reflecting reproduction) was observed at $20{ }^{\circ} \mathrm{C}$ (Fig.4). In comparison, reproduction of the plant parasitic nematode Heterodera cajani was greatest at $25^{\circ} \mathrm{C}$ [5].

Estimates of a generation time $\left(\mathrm{T}_{\min }\right)$ for P. maupasi are of the same magnitude as for a range of other free-living nematodes, including its close relative $P$. pacificus [6]. In accordance with results on nematodes from sewage treatment plants [7], the life-span of P. maupasi decreased with increasing temperature, except when $P$. maupasi became $2^{\text {nd }}$ generation "dauerlarvae". In this arrested condition $P$. maupasi obviously survives unfavourable conditions longer, also at relatively high temperatures such as $20^{\circ} \mathrm{C}$. Arrestment may be a result of crowding in combination with reduced food supplies and increased concentration of wastes. In nature such situations may occur when a food source is depleting. Surviving "dauerlarvae" was able to resume their development on fresh Nigon's medium, comparable to renewal of a natural food base.

At a depth of $5 \mathrm{~cm}$, Danish soil temperatures fluctuate between minus 1 and plus $9^{\circ} \mathrm{C}$ in the colder period (November to March) [8]. Temperatures about $5^{\circ} \mathrm{C}$ may last for several days or weeks in this period. At such low temperatures $P$. maupasi is able to survive; otherwise this species would not be present in the experimental field. If temperatures approach $10^{\circ} \mathrm{C}$ for a week $P$. maupasi is be able to complete its entire life cycle. During the warmer period (May to September), soil temperatures fluctuate between 10 and $20^{\circ} \mathrm{C}$ [8], which allow P. maupasi populations to survive and reproduce if other important factors, such as soil moisture [9], are favourable.

Table 1. Estimation of 'the Net Reproductive Rate' $\left(\mathbf{R}_{\mathbf{0}}\right)$ and 'the Intrinsic Rate of Natural Increase' (r) of $P$. maupasi

\begin{tabular}{|c|c|c|}
\hline Temperature $^{\mathbf{}} \mathbf{C}$ & $\mathbf{R}_{\mathbf{0}}$ & $\mathbf{r}_{\left(\text {Days }^{-1}\right)}(\mathbf{1}$ Day=24 Hours $)$ \\
\hline \hline 5 & 0 & - \\
\hline 10 & 104 & 0.7 \\
\hline 15 & 150 & 1.0 \\
\hline 20 & 129 & 1.2 \\
\hline 25 & 35 & 1.2 \\
\hline 30 & 0 & - \\
\hline
\end{tabular}

The reproductive capacity may be expressed by 'the intrinsic rate of natural increase' (r), which was estimated as described below. The number of eggs, produced by an average fertile nematode, are approximately $\left(\max .2^{\text {nd }}\right.$ generation/ $\max$. $1^{\text {st }}$ generation). This is a rough estimate of 'the net reproductive rate' $\left(\mathrm{R}_{\mathrm{o}}\right)$ (Table $\left.\mathbf{1}\right)$. Furthermore, an estimate of the (minimum) generation time $\left(\mathrm{T}_{\min }\right.$, days) makes it possible to estimate $r$ by the formula: $r=\left(\log _{e} R_{o}\right) / T_{\min }$ (Table 1$)$. 'The intrinsic rate of natural increase' is a sensitive coefficient in the logistic model for density-dependent population growth: $\mathrm{dN} / \mathrm{dt}=\mathrm{rN}((\mathrm{K}-$ $\mathrm{N}) / \mathrm{K}$ ) ( $\mathrm{K}$ is the environmental carrying capacity and $\mathrm{N}$ is the actual population size).
The coefficient (r) may be influenced by external factors such as temperature and chemicals. If 'the intrinsic rate of natural increase' is altered for a significant number of soil organisms it could ultimately result in changes in the rate of decomposition of organic matter in the soil ecosystem.

\section{CONCLUSION}

$P$. maupasi has a large reproductive potential (r: $0.7-1.2$ days $^{-1}$ ) between 10 and $25^{\circ} \mathrm{C}$, which means that $P$. maupasi has the ability to restore its population very fast in mild or warm periods of the year. Most likely population decline in such favourable periods is caused by lack of food, enemies or infections. Between 15 and $25^{\circ} \mathrm{C} \mathrm{r}$ is remarkably stable between 1 and 1.2 days $^{-1}$ (Table 1). These r-values are of the same magnitude as those found for several bacterial feeding nematodes [9].

\section{ACKNOWLEDGEMENTS}

Hanne Rawat is appreciated for her competent technical work and we also want to thank Peter Holter and Hans-Ole Kraglund for their valuable scientific contribution to this investigation.

\section{CONFLICT OF INTEREST}

None declared.

\section{REFERENCES}

[1] Hirschmann H. Über das Vorkommen zweier Mundhöhlentypen bei Diplogaster lheritieri Maupas und Diplogaster biformis n.sp. und die Entstehung dieser hermaphroditischen Art aus Diplogaster lheritieri. Zoologische Jahrbücher. Abteilung für Systematik, Ökologie und Geographie der Tiere 1951; 80: 132-70

[2] Herrmann M, Mayer WE, Sommer RJ. Nematodes of the genus Pristionchus are closely associated with scarab beetles and the Colorado potato beetle in Western Europe. Zoology 2006; 109: 96-108.

[3] Sohlenius B. Studies of the interactions between Mesodiplogaster sp. and other rhabditid nematodes and a protozoan. Pedobiologia 1968; 8: 340-4.

[4] Hooper DJ. Culturing nematodes and related experimental techniques In: Southey JF, Ed. Laboratory Methods for Work with Plant and Soil Nematodes, Her Majesty's Stationery Office, London 1986, pp. 13357.

[5] Singh M, Sharmas SB. Infectivity, Development, and Reproduction of Heterodera cajani on Pigeonpea: Influence of soil moisture and temperature. J Nematol 1995; 27(3): 370-7.

[6] Vancoppenolle B, Borgonie G, Coomans A. Generation times of some free-living nematodes cultured at three temperatures. Nematology 1996; 1(1): 15-8.

[7] Woombs M, Laybourn-Parry J. Growth, reproduction and longevity in nematodes from sewage treatment plants. Oecologia (Berlin) 1984; 64: 168-72.

[8] Jensen HE, Jensen SE, Eds. Jordfysik og jordbrugs-meteorologi. DSR Forlag, Copenhagen 2001; pp. 556.

[9] Venette RC, Ferris H. Thermal constraints to population growth of bacterial-feeding nematodes, Soil Biol Biochem 1997; 29: 63-74. 